\title{
Una aproximación descriptiva a la propiedad intelectual de bajo valor agregado y distorsión de la competencia: Caso Estados Unidos
}

\section{A first descriptive approach on low value added intellectual property and competition distortion: Case of the US}

\section{Mario De La Puente}

Internacionalista por la Universidad del Norte (Col.); máster en Relaciones Económicas Internacionales por la Universidad Rey Juan Carlos (España); doctorado en Análisis Económico Internacional por la Universidad Rey Juan Carlos de Madrid, España. Profesor del Departamento de Ciencia Política y Relaciones Internacionales, Universidad del Norte (Col.); investigador del grupo de investigación Agenda Internacional.

Correo electrónico:Mdelapuente@uninorte.edu.co

\section{Resumen}

El presente artículo de investigación tiene como objetivo analizar los inconvenientes del otorgamiento de patentes de bajo valor agregado, consideradas obvias sobre el funcionamiento del libre mercado bajo la perspectiva teórica de libre mercado para el caso de Estados Unidos. Se encuentran fuertes vacíos en la normativa estadounidense referente a los inventos considerados obvios, que desincentivan la innovación empresarial como consecuencia del flujo imperfecto de información que limita el conocimiento de patentes preexistentes y aumento artificial de costos al consumidor. El método de estudio es el análisis de datos recogidos de diversas fuentes oficiales y artículos de investigación sobre el tema.

Palabras clave: Distorsión, patente, derecho de competencia, eficiencia de mercado.

\begin{abstract}
This research paper analyzes the disadvantages of patenting low added value inventions considered obvious on the operation of the free market under the free market theoretical perspective for the U.S case. Gaps are strong in relation to considered obvious inventions which discourages business innovation as a result of imperfect information flow limiting knowledge of existing patents. Also discourage competition from small and micro enterprises who choose to go the legal system to maintain market share. The analysis method is based on data research form different official sources.
\end{abstract}

Keyword: Distortion, patent, competition right, market efficiency.

\section{Résumé}

Ce document de recherche vise à analyser les inconvénients de l'octroi de brevets à faible valeur ajoutée, considérée comme évidente sur le fonctionnement du marché libre dans la perspective théorique du libre marché pour le cas des États-Unis. Ils sont drénormes lacunes en ce qui concerne les inventions considérées évidentes qui découragent linnovation des entreprises en raison de l>écoulement de linformation imparfaite qui limite la connaissance des brevets existants et augmentation artificielle des consommateurs américains coûte règlements. La méthode deétude est $\mathrm{l}$ > analyse des données recueillies auprès de diverses sources officielles et des documents de recherche sur le sujet.

Mots-clés: Distorsion, droit des brevets, la concurrence, l〉efficacité du marché. 



\section{Una aproximación descriptiva a la propiedad intelectual de bajo valor agregado y distorsión de la competencia: Caso Estados Unidos"}

Mario De La Puente

\section{INTRODUCCIÓN}

La finalidad última de la competencia es asegurar el funcionamiento lo más eficientemente posible del mercado caracterizado por las interacciones de información, a partir del intercambio de bienes y servicios. Las prácticas anticompetitivas se fundamentan sobre la base del acaparamiento del mercado, utilizando instrumentos privativos exclusivos o ventajas que profundizan la competencia imperfecta. En ese sentido, el derecho de propiedad intelectual a partir del otorgamiento de patentes por concepto de utilidad o creación de un invento o procedimiento en muchos casos cuestionables por su percepción de obviedad World Intellectual Property Organization - WIPO (2014), distorsiona el mercado en materia de precios a través de cambios en los costos totales de elaboración de un bien y utilización de un procedimiento limitando el acceso de este al nicho de mercado objetivo, a través de una discriminación de precios y limitaciones legales Coastal Data Information Program - CDIP (2011).

Lo anterior provoca un conflicto filosófico entre el derecho de propiedad intelectual único del sujeto y el derecho de competencia colectivo (Hayek, 1948). La legislación de patentes exige luchar contra copias e imitaciones de productos

* El presente artículo es resultado de investigación de la tesis doctoral: "Economía del Turismo de Salud: Caso colombiano", financiado por I.T Metropolitano, 2013. 
patentados salvaguardando el derecho al mantenimiento y reconocimiento de la propiedad intelectual (Patent Act, 1793), fundamental en una economía de mercado, mientras que los derechos de competencia buscan la igualdad relativa de condiciones para empresas oferentes de sus bienes y servicios a los consumidores intermedios o finales (Plant, 1974, p. 24). Los principios fundamentales en que se basa el sistema de patentes se ha fijado con el fin de promover la innovación al otorgar derechos por utilidad y creación que revisten con más probabilidad de interés para el público en general, protegiendo las invenciones mas no los descubrimientos, y fijando condiciones de patentabilidad de modo que no se puedan conceder patentes a invenciones que carezcan de innovación (Penrose, 1974. p. 40). Sin embargo, el sistema de patentes se ha tomado como una oportunidad de ingresos derivados del otorgamiento de licencias a terceros que quieran utilizar un invento o procedimiento, sino también como una oportunidad de mover el sistema legal que incentiva múltiples demandas de creadores hacia empresas que (en varios casos), sin conocimiento de la existencia de un producto patentado, se ven sumergidos en litigios interminables que desincentivan la producción nacional y perpetúan la incertidumbre para futuras creaciones. Este es el caso de Estados Unidos, donde la creciente creación de productos poco innovadores con sus respectivas patentes perjudica la creación, producción y lanzamiento al mercado de nuevos utensilios por miedo a litigios, culminando en el pago de licencias que aumentan los precios finales de los bienes y servicios comercializables o la exclusión del producto del mercado limitando la posibilidad de elección de consumidores (CDIP, 2011).

El presente artículo analiza las causas y consecuencias del establecimiento de patentes con poco valor agregado que perpetua la incertidumbre sobre pequeñas y medianas empresas en Estados Unidos que, buscando mantener intacto su capital, optan por un desincentivo en la creación de productos innovadores para el consumo. La primera parte del presente artículo menciona las generalidades del marco legal estadounidense en materia de patentes que permite una aproximación al entendimiento normativo norteamericano, haciendo énfasis en las normas referentes a la constitución y condicionamiento de otorgamiento de patentes con el fin de conocer la legislación interna. Para esto se invocan las principales leyes constitutivas del sistema de patentes en Estados Unidos y el funcionamiento de los organismos encargados de la administración de propiedad intelectual, así como el derecho a la competencia con fines de ausencia de monopolios con el fin de conocer las contradicciones normativas en cuanto a la prevalencia del derecho individual sobre el derecho colectivo. La segunda parte analiza la incertidumbre de las empresas norteamericanas en el establecimiento de patentes de bajo valor agregado que desincentiva la innovación y la competencia a pesar de que la finalidad última del otorgamiento de patentes es la creación de productos considerados innovadores con utilidad práctica para el bien común. Lo anterior, a partir de un análisis económico-filosófico donde se realza la necesidad de la operación de libre mercado que permita una localización eficiente de recursos para el bienestar general. La tercera parte estudia el impacto del 
otorgamiento de patentes de bajo valor agregado sobre el consumo final entendido como la escasez en la adquisición de bienes innovadores por parte de empresas que por temor a demandas de violación de propiedad intelectual optan por no lanzar al mercado dichos productos y retrasar su salida, previendo consecuencias negativas en sus ganancias periódicas. Lo anterior con el apoyo de gráficas que permitan ilustrar los argumentos expuestos.

Por último se exponen una serie de recomendaciones para mejorar el sistema de otorgamiento de una patente a partir del verdadero valor agregado que este represente para la sociedad. Finalmente, se concluye, mencionando la importancia de la prevalencia de la competencia sobre el derecho de los otorgamientos patentes sin auténtico valor agregado que limita la planeación estratégica de mercadeo, distribución y ventas al consumidor final distorsionando el mercado de bienes generales a partir de la reivindicación del derecho de propiedad intelectual.

\section{PROPIEDAD INTELECTUAL, COMPETENCIA Y MARCO LEGAL ESTADOUNIDENSE}

Desde la época colonial, los inventores de productos considerados de gran utilidad recurrían a los gobiernos de sus colonias con el fin de garantizar el uso exclusivo del producto o proceso. La primera garantía de derecho de uso exclusivo fue dada en la colonia de Massachusetts en 1641 a Samuel Winsolw, en el proceso de elaboración de sal por diez años siendo extraoficialmente conocida como la primera patente en Norteamérica (Mokyr, 1990). Así, varias colonias otorgaban derechos de propiedad sobre bienes y/procesos a personas especificas (generalmente conocidos con intereses económicos que involucraban a los representantes colonos). A finales del siglo XVIII las colonias adoptaron normas similares para el otorgamiento de derechos de propiedad intelectual que estandarizaron procedimientos para la solicitud y otorgamiento de patentes, al ser Carolina del Sur el primer Estado en aprobarla en 1784 (Plant, 1974. pp. 24) caracterizada por el otorgamiento de derecho de explotación de un procedimiento o articulo por 14 años (PWC, 2014).

Sin embargo, al existir diferencias fundamentales en la normativa comparada había riesgo de violación de patentes en otros Estados, aumentando los costos de protección de derechos de propiedad intelectual (Watson, 2013. pp. 123-125). En 1787 Estados Unidos adopta mediante la Constitución Nacional leyes inclusivas de derechos de protección de propiedad intelectual vía patentes a través del aseguramiento exclusivo de derecho de explotación de un invento, procedimiento o descubrimiento por un periodo de tiempo determinado (U.S Copyright Office, 2008). En 1790 se aprueba el primer estatuto de patentes donde se resalta el otorgamiento de derechos de explotación de propiedad intelectual por 14 años (Patent Act, 1836) (a pesar de las críticas de varios sectores académicos y empresariales que alegaron que la comercialización particular a lo largo del territorio nacional y en el extranjero tardaría más del periodo otorgado de explotación de un invento o 
procedimiento) y la imposibilidad de que extranjeros obtuviesen patentes en Estados Unidos (Jaffe, 2002).

En 1793 se confiere la ley de patentes que remplazó el estatuto de 1790 que definía la patente como una manufactura, máquina o arte útil, así como una composición de índole musical o científica (Hurt, 1966. pp. 421-432). También aplicaba una mejora a una máquina, manufactura, o elaboración de arte lo que significaba en la práctica un limbo jurídico aplicable para cualquier modificación sensible al cambio original de invención (esta es la base de las dificultades actuales en el otorgamiento de patentes frente al derecho de libre competencia) donde, aun cuando la utilidad del producto fuese dudoso, la amplitud de la normativa permitía mayor facilidad en el otorgamiento de la patente. En ese sentido, entre 1790 y 1793 solo se otorgaron 57 patentes (Watson, 2013. pp. 124), mientras que a partir de 1793 hasta 1836 se otorgaron más de 10000 patentes debido a la amplitud y ambigüedad de la norma (muchas de ellas de baja calidad y sin utilidad práctica). Esta situación provocó un aumento sustancial en el número de demandas entre los dueños de las patentes y empresas que desconocían la existencia de patentes frente a productos que consideraban innovadores.

Asimismo, el número de solicitudes de patentes sobrepasó la capacidad de trámite de la recién creada Oficina de Patentes y Marca Registrada, la cual en su momento no contaba con capacidad administrativa (WIPO, 2013), financiera y de personal para tramitar las crecientes solicitudes. En 1836 se aprobó una reforma a la Ley de Patentes de 1793 de las cuales resalta la modificación de la Oficina de Patentes adscrita al Departamento de Estado, el conocimiento público de aplicación para el otorgamiento de una patente con el fin de evitar la aplicación de una patente de productos ya creados con el fin de descongestionar las solicitudes hábiles, la extensión por siete años de la duración de una patente como respuesta a las múltiples críticas por la corta duración del derecho de propiedad y el permiso de aplicación y obtención de patentes nacionales por parte de extranjeros (Gould, 1995. pp. 23-25).

En 1849 la Oficina de Patentes pasó a jurisdicción del Departamento del Interior. En 1952 la estructura básica de la Ley de Patentes fue modificada resaltando la necesidad de descripción del inventor, no solo de su invento, sino también la descripción de la base de su aporte a la sociedad. Lo anterior con el fin de no otorgar patentes a productos obvios donde el solicitante de la patente se aprovechara de un procedimiento o producto particular de un campo específico del conocimiento.

En 1982 se crea la Corte de Apelaciones del Circuito Federal con el fin de atender únicamente a casos donde la violación de una patente, así como la reclamación por concepto del no otorgamiento de esta se resuelva de forma rápida y especializada. En 2011, se promulga la Ley de Inventos Leahy-Smith cambiando el sistema de patentes en el que se prioriza al solicitante que patente primero un invento antes que su creador (Cohen, 2000, pp. 98) (aun cuando este no haya patentado el invento o procedimiento). Finalmente, después de la adopción del documento declaratorio de la Ronda de Uruguay por medio del cual el GAAT pasa a ser la OMC, Estados Unidos amplia el periodo de beneficio de explotación de patente de 17 a 20 años a partir 
de la obtención de esta. En materia de competencia, en 1890, se promulga la Ley Sherman anti-monopolio con el fin de restablecer el equilibrio de mercado a partir de la garantía de condiciones equitativas que fomenten la competencia que beneficia al consumidor final (Denison, 1979). Lo anterior como respuesta a la alta concentración de industrias en manos de un competidor (caso Estándar Oil de John Rockefeller) a partir de la regulación de precios de insumos con el fin de evitar la creación de carteles, acuerdos extraoficiales, regulación del poder de mercado de un competidor en comparación con el resto y el no otorgamiento o defensa de patentes de inventos de gran alcance en cuanto a utilidad se refiere para la población estadounidense.

La Ley Antimonopolio fue el resultado de constantes críticas al derecho exclusivo de explotación de inventos o procedimientos en un entorno de crisis económica, donde se tenía una percepción general de que las patentes limitaban la competencia y aumentaban los costos fijos de producción y distribución de mercancías y servicios.

Sin embargo, las patentes no se vieron en amenaza de desaparecer, más aun, el número total de otorgamiento de las estas aumentó de forma exponencial. El siguiente gráfico expone el crecimiento de solicitudes de patentes en Estados Unidos durante el periodo 1970-2012.

Figura1. Evolución de solicitudes de patentes por parte de nacionales y extranjeros en Estados Unidos: 1970-2012

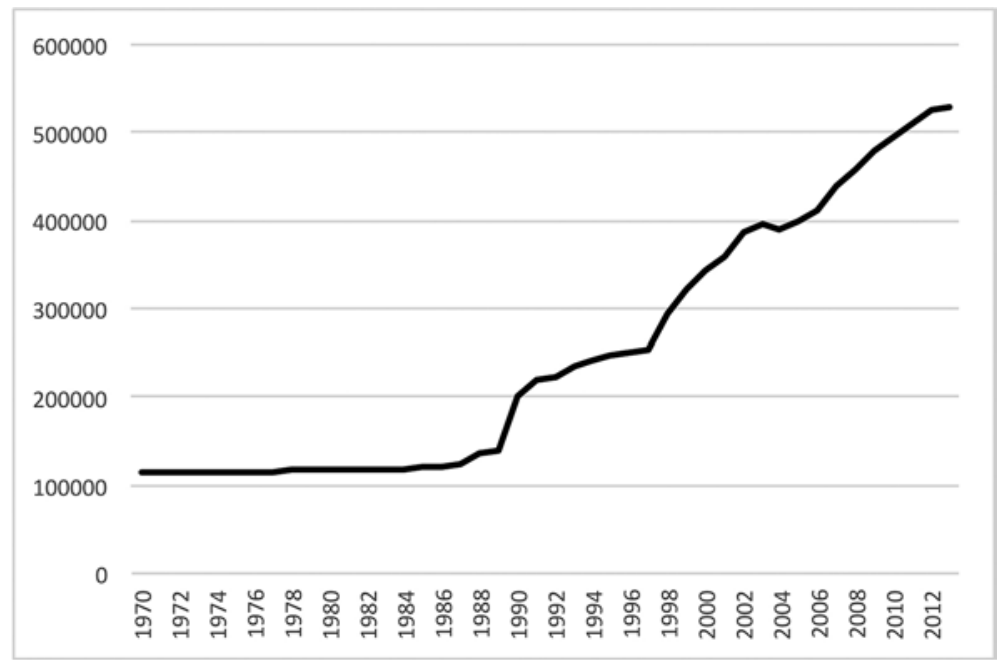

Fuente: Elaboración de autor.

La posibilidad de que extranjeros soliciten patentes en suelo norteamericano ha aumentado el número de solicitudes de forma notable durante los últimos años en diversos campos del conocimiento, siendo el sector de la tecnología computacional 
y médica líderes. La siguiente figura muestra la distribución porcentual de las solicitudes de patentes por sectores productivos para el 2013. En la actualidad, la Oficina de Patentes y Marca Registrada de Estados Unidos es una agencia adscrita al Departamento de Comercio, encargada del otorgar patentes a quienes las soliciten, mantener informado al Departamento de Comercio sobre todo lo relacionado con la propiedad industrial y administrar los datos estadísticos de propiedad intelectual, industrial, pago por concepto de las mismas y la protección de marcas registradas.

Figura 2. Distribución porcentual de solicitudes de patentes en 2013

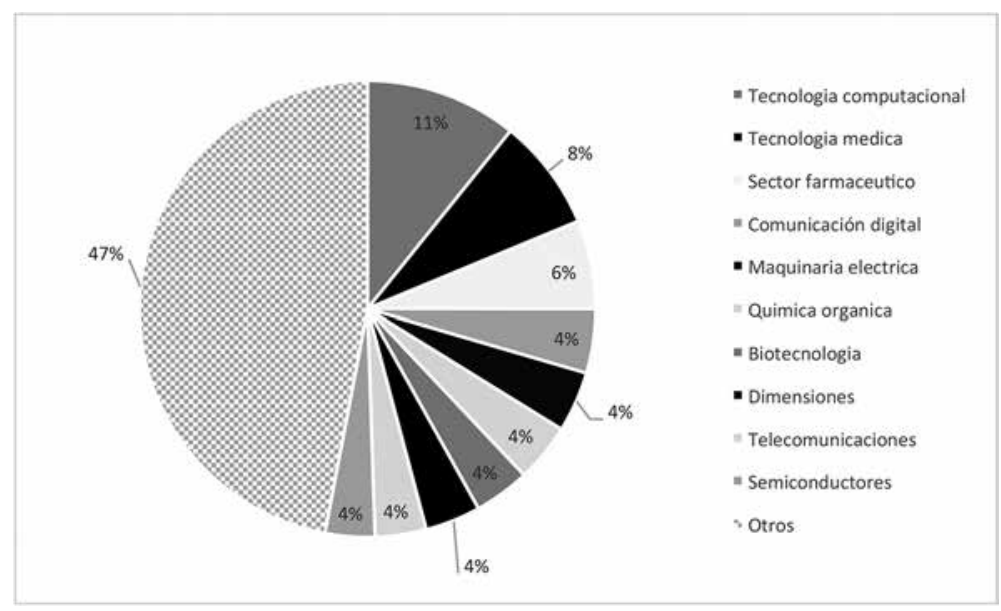

Fuente: Elaboración de autor.

La forma en que la Oficina de Patentes otorga el beneficio a determinado solicitante es un tanto compleja y requiere una precisión absoluta al momento de presentar la solicitud. Como primer requisito una patente se otorga cuando no es obvio el resultado obtenido (existe una ambigüedad en el concepto de obviedad que crea un vacío legal), es considerado novedoso y útil, a su vez tiene que ser descrito minuciosamente. Dentro de esta descripción se debe incluir el nombre del invento, resumen del mismo, procedimiento que se siguió para llegar a este, gráficos, dibujos, entre otros; todo aquello que permita diferenciar el invento de algún otro y que muestre características únicas que se obtienen por medio del procedimiento antes descrito. Se manejan tres tipos de patentes que se complementan entre sí: las patentes de diseño, las patentes de utilidad y patentes vegetales. Las patentes de diseño se utilizan básicamente para productos manufacturados, donde se le otorga al inventor la garantía de su autoría, las patentes de utilidad permiten una mayor protección a nuevos inventos o procesos, son generalmente usadas cuando se ha mejorado algo ya existente así como el otorgamiento del derecho de explotación de su invento o procedimiento. Por su parte, las patentes vegetales son usadas cuando se ha mejorado 
algo ya existente. La Oficina de Patentes solo otorga patentes a nivel nacional, sin embargo recibe solicitudes de otras naciones siguiendo las mismas bases de patentabilidad que se aplican a ciudadanos estadounidenses.

\section{PATENTES E INCERTIDUMBRE A LA INNOVACIÓN}

Al considerarse la patente como una institución jurídica dada, existe la concepción que la equipara más como un derecho personal que como un monopolio de derecho, dadas las implicaciones negativas para competencia en materia de incertidumbre en cuanto a la creación de nuevos bienes y limitación de flujo de información (Buchanan, 1986). En ese sentido el derecho exclusivo del inventor de otorgar licencias excluye a la sociedad del goce y disfrute de la proliferación de inventos que suponen un beneficio colectivo. Si a esto se suma la imposibilidad de conocimiento de productos que violen una patente resulta en una distorsión del libre funcionamiento del mercado donde se desvía el ejercicio de la función empresarial, impidiendo la solución de problemas cotidianos y especializados, además del acceso a sus soluciones. Si bien es necesaria la protección de derechos de propiedad intelectual, el otorgamiento superfluo de patentes a inventos considerados obvios como resultado de una limitación en el estudio de patentabilidad, producto del desborde en la capacidad de respuesta de la Oficina de Patentes, produce una incertidumbre continua a empresarios que buscan suministrar bienes y servicios innovadores al público que desconocen la existencia de patentes de productos inventados y sacados al mercado (Cooper, 1938. pp. 805).

El resultado es el desincentivo a crear bienes considerados innovadores por miedo de acciones legales o pago de licencias que aumenta los costos totales de producción, limitándoles su competitividad en el interior del país. Así, la calidad pobre de las patentes además del muy dinámico sistema legal estadounidense donde las demandas son iniciativas comunes crea un efecto anticompetitivo y concentra el poder de mercado, afectando al beneficio colectivo para los consumidores. La causa principal del otorgamiento de patentes de bajo valor agregado consideradas obvias es la ausencia de un procedimiento normativo administrativo que permita la revisión del aporte de una patente luego de haberse concedido a su propietario (Benegas, 1999, pp. 121-147). En la actualidad la Oficina de Patentes y Marca Registrada analiza y discute la patentabilidad de un producto únicamente con el aspirante mientras que terceros solo se involucran cuando tiene patentes en su poder y consideran que el aspirante puede incurrir en riesgo de violación de la patente existente, previo envío de carta de protesta al director de Oficina Federal (Foray, 1994. pp. 98-99).

Debido a la escasa participación de terceros en el proceso de otorgamiento de unas patentes, el Congreso aprobó la Ley de Procedimiento Limitado que permite a terceros participar en la reexaminación de una patente una vez se otorgue en primera instancia. Sin embargo, la falta de especificidad de la norma en cuanto a la documentación probatoria y los términos del procedimiento que debe presentar el tercero en el proceso de reexaminación no ha incentivado el uso masivo de la Ley 
(McKinsey, 2012). En ese sentido, la forma más efectiva de resolver una imputación de violación de patente es mediante el litigio, sin embargo, este es extremadamente costoso y lento, perjudicando al dueño de la patente en cuanto a la explotación de su invento o procedimiento durante un periodo de tiempo prolongado. La intención de un nuevo procedimiento administrativo de reexaminación de una patente es, por un lado, equiparar a terceros involucrados con el cuerpo administrativo y el solicitante otorgándole más participación que permita eliminar patentes consideradas obvias y sin un verdadero valor agregado para la utilidad o innovación en la sociedad (WIPO, 2014). Por otro lado, al limitar la participación de terceros en la reexaminación de patentes se busca evitar el hostigamiento de estos hacia los solicitantes por un invento o procedimiento que represente una fuente de ingresos considerable.

Sin embargo, aun cuando la vigencia de una patente se mantiene luego del proceso de reexaminación, estos pueden acudir a instancias judiciales para defender sus argumentos causando congestión en el sistema judicial, en el sistema de administración de patentes y una prolongación en la decisión final que cuesta recursos monetarios para efectos de inversión y otorgamiento de licencias. A pesar de esto, el número de solicitudes de patentes se encuentra en aumento, así como el otorgamiento de estas dentro y fuera del territorio estadounidense. La siguiente figura muestra las solicitudes de patentes y otorgamientos de las mismas en el país durante el periodo 1999-2013, mientras el segundo muestra las patentes solicitadas y otorgadas por no residentes en el mismo periodo.

Existe otra situación que permite el otorgamiento de patentes de baja calidad consideradas obvias que fomentan la incertidumbre a la innovación y desincentivan la producción de dichos bienes. Esta es la saturación de solicitudes de patentes y reexaminación de estas frente a los recursos monetarios, de personal y de equipos con el que cuenta la Oficina de Patentes.

En el 2002 el Comité Asesor de Patentes (organismo adscrito a la rama legislativa con funciones de asesoría a la Oficina de Patentes) advirtió sobre la crisis que genera la escasez de fondos públicos para el funcionamiento general de la institución, que resulta en una ampliación del periodo de respuesta frente a una solicitud de patentes, la reexaminación de una patente vigente, entre otros asuntos de su competencia ${ }^{1}$. Esta situación provoca que las evaluaciones de originalidad y valor agregado de una solicitud de patente así como reexaminación sean de baja calidad, permitiendo el otorgamiento de patentes a inventos y procedimientos considerados obvios por el sector privado y que generan incertidumbre en el funcionamiento general del mercado de diversos bienes y servicios. La ley de patentes impide patentar si las diferencias entre el invento reivindicado y un invento preexistente son tales que el tema en cuestión en su conjunto habría sido evidente en el momento en que se hizo la invención a una persona que tenga experiencia ordinaria en la técnica entendido como la posibilidad general de creación ordinaria de un producto por personas no expertas en un campo del conocimiento bajo la denominación de concepto de utilidad.

1 Para una búsqueda sobre el pronunciamiento completo de la Oficina de Patentes, Mochon (2012). 
Figura 3. Patentes solicitadas y otorgadas en Estados Unidos por residentes: 1999-2013

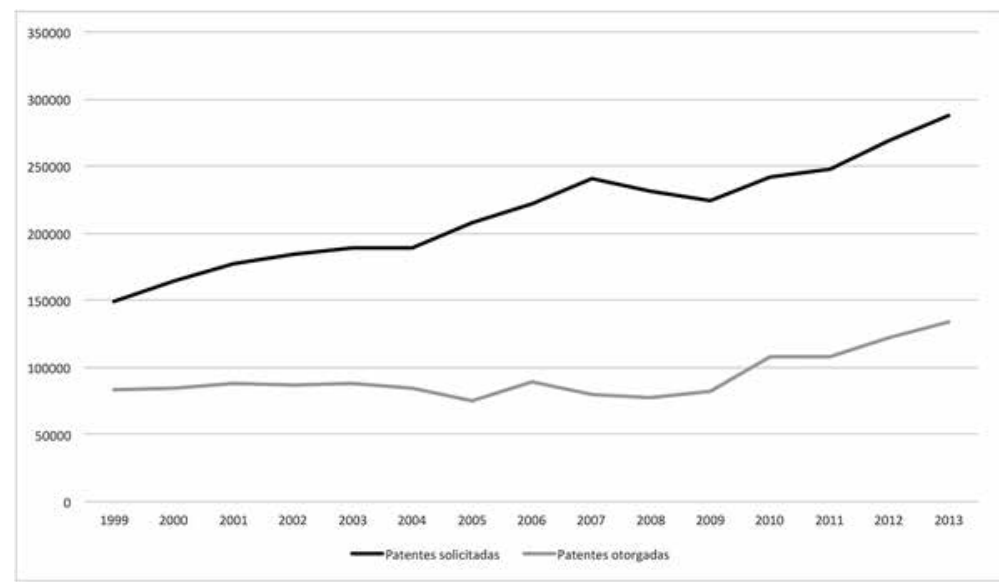

Fuente: Elaboración de autor.

Figura 4. Patentes solicitadas y otorgadas en Estados Unidos por no residentes: 1999-2013

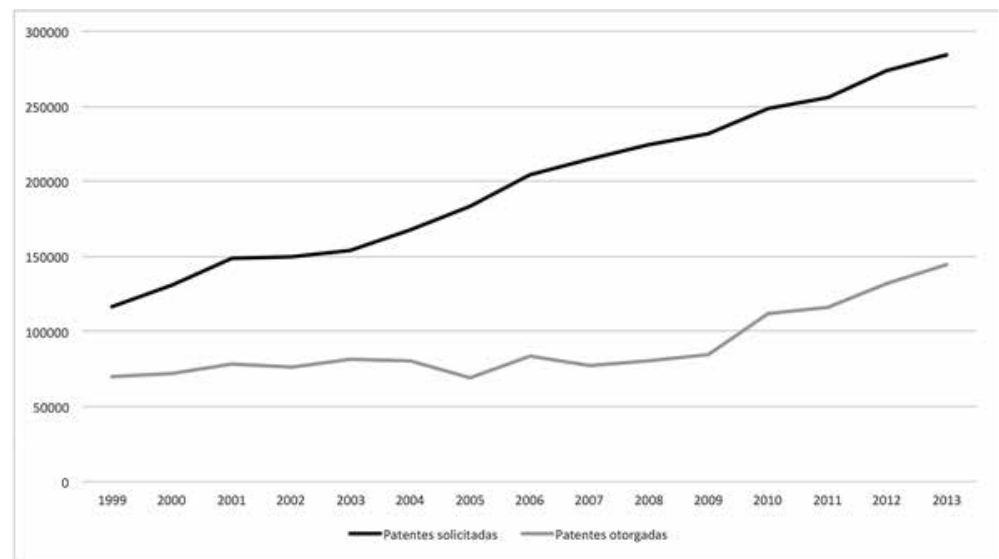

Fuente: Elaboración de autor.

La no obviedad de un invento se entiende como el desarrollo lo suficientemente técnico de un producto que amerita su patentabilidad (Mochon, 2012. pp. 24-25). La aplicación adecuada de este principio de la Ley de Patentes es indispensable para prevenir el monopolio de derecho de explotación de un invento que popularmente puede ser considerado como obvio y sin valor agregado para la población, y el cual puede encontrarse ya bajo dominio de la población (evitando litigios por violación 
de patente). Generalmente en caso de litigio por violación de patente cuando esta se considera obvia, los jueces suelen solicitar una prueba comercial y otra de sugestión.

El primero suele establecerse mediante pruebas de tiempo donde un invento satisface una necesidad de largo plazo que otros no han podido satisfacer (aunque existen varios críticos que alegan que una prueba comercial no implica la no obviedad de un invento que se dirija a un nicho específico de mercado que no satisfaga al grueso de la población, además que el mercadeo y campañas publicitarias pueden crear una necesidad en la población aun cuando el invento o procedimiento no sea objetivamente indispensable para el consumidor final) (Cuban, 2013. pp. 26-27).

La segunda prueba se basa en el análisis de no obviedad para un experto en el área en el cual se desarrolla el invento siendo la no obviedad como lo que no va más allá del progreso ordinario de la tecnología (CDIP, 2012), que se deduce de modo simple y lógico a partir del estado de la técnica de elaboración del invento o procedimiento. Infortunadamente, la ambigüedad de estas pruebas sumado a la falta de capacidad operativa de la Oficina de Patentes frente al crecimiento interanual de las solicitudes dan como resultado el mantenimiento y vigencia de patentes de bajo valor agregado consideradas por el público en general como obvias, distorsionando la competencia interna. La siguiente figura muestra el crecimiento de las patentes vigentes de residentes, no residentes y solicitadas en el extranjero durante el periodo 1999-2013.

Figura 5. Crecimiento de las patentes vigentes de residentes, no residentes y solicitadas en el extranjero durante el periodo 1999-2013

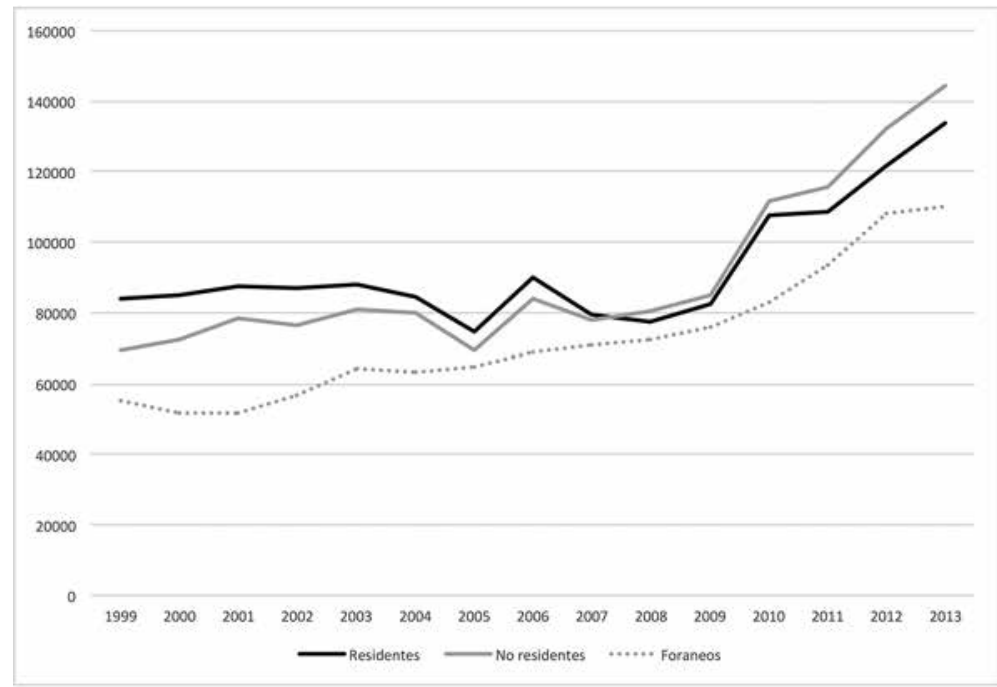

Fuente: Elaboración de autor. 


\section{PROPIEDAD INTELECTUAL SOBRE EL BENEFICIO NETO DEL CONSUMIDOR}

El establecimiento de baja calidad en diversas áreas del conocimiento representa en sí un perjuicio neto para el consumidor que busca mejorar sus niveles de utilidad a través de la adquisición de bienes y servicios. La patente (principalmente de productos y procedimientos considerados obvios) es en sí misma un derecho monopolístico que les permite a los propietarios un dominio de mercado a través del otorgamiento de licencias que termina en muchos casos en un incremento de precios del producto y servicio para el consumidor final (Pérez y Soto, 2013. pp. 307).

Este derecho monopolístico es en sí violatorio del principio de libre competencia enmarcada en las ciencias económicas en esquemas de economías de mercado, aun cuando en la normativa estadounidense no exista el concepto de monopolio entorno a la figura de la patente. Los resultados son la inaccesibilidad de productos (en muchos casos de primera necesidad como medicamentos de mayor concentración química que tengan efectos más intensos sobre un paciente) que limitan la elección del consumidor creando una situación de escasez ficticia donde si bien el recurso se encuentra disponible para este, no puede adquirirlo debido a incrementos ficticios de precios por efectos diferentes en materia económica para su producción, distribución y comercialización (Pérez y Soto, 2013. pp. 20).

Si bien en una economía regida por el principio de propiedad privada es importante salvaguardar el derecho de propiedad intelectual, este se encuentra en muchos casos por encima del beneficio global de acceso a bienes y servicios sin manipulación extraoficial de precios de los consumidores que se ven en muchos casos perjudicados por el monopolio legal de dominio de una idea o invento.

En ese sentido, los principales costos de una patente para la sociedad consumidora, productora e inventora en Estados Unidos ronda los US\$150 mil millones, un incremento de más del 100\% respeto a 2009, según McKinsey y Co (2012), siendo el estorbo al progreso técnico uno de los principales obstáculos a la innovación ${ }^{2}$, la producción y comercialización de bienes y procedimientos anti-económicos por parte de competidores que buscan inventar alrededor de una patente existente para evitar litigios, y la distorsión de incentivos de la actividad inventiva hacia productos más fácilmente patentables resultando en productos de muy bajo valor agregado en muchos casos considerados obvios. Sin embargo, los efectos perjudiciales de la obtención de patentes de alto y bajo valor agregado no solo se limitan al consumidor final, sino también distorsiona toda la dinámica de principios empresariales norteamericanos donde una empresa o persona natural que vende un producto patentado opta por ceñirse en muchos casos únicamente a litigios por violación de su propiedad intelectual y enfocarse en mejorar los elementos y la funcionalidad del invento o procedimiento en cuestión haciendo el mercado menos eficiente.

2 Informe McKinsey y Co. Recuperado de file://C:/Users/mdelapuente/Downloads/Generating _ value_in_generics_June $\% 202013 \% 20(1) . p d f$ 
Esta situación se presenta principalmente en empresas micro y de pequeño tamaño, donde la violación de una patente por parte de otra de mayor tamaño y músculo financiero limita el accionar competitivo de la primera, optando por la vía legal como recurso único para obtener cuota de mercado. Esta situación se debe principalmente al dinamismo del sistema legal estadounidense y la utilización sucesiva del recurso de demanda como método de resolución de conflictos que si bien se acogen a los principios constitucionales internos, ciertamente desincentiva la competencia en términos económicos, ya que los pequeños y microempresarios ven en la demanda un camino más corto para acaparar mayor cuota de mercado de un bien o proceso. La siguiente figura muestra el crecimiento sostenido de litigios por violación de derechos de propiedad intelectual en Estados Unidos durante el periodo 1991-2013.

Figura 6. Crecimiento sostenido de litigios por violación de derechos de propiedad intelectual en Estados Unidos durante el periodo 1991-2013

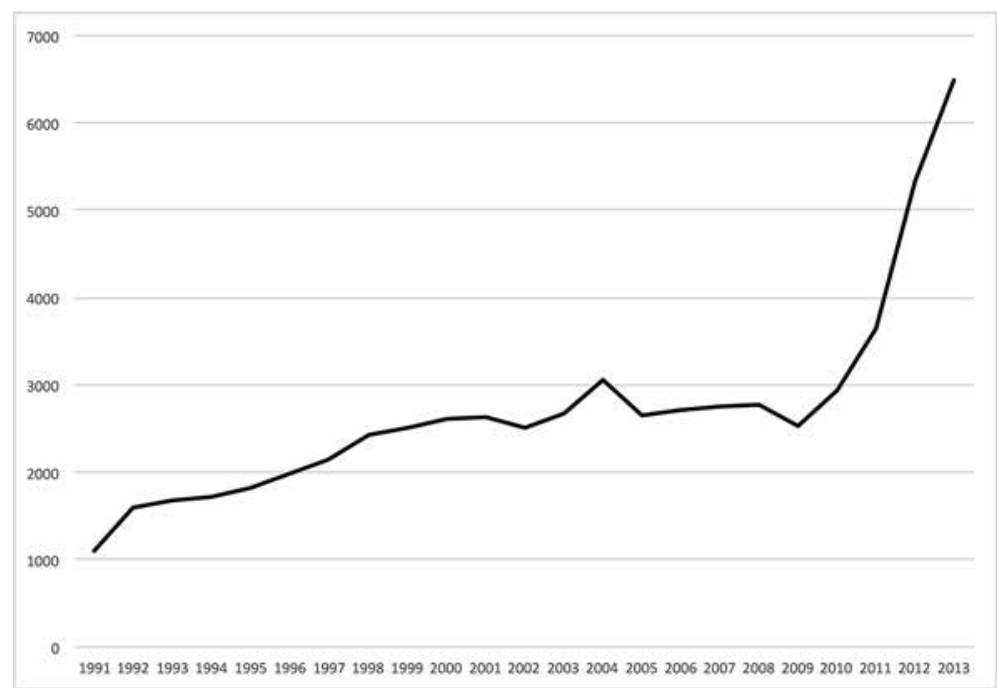

Fuente: Elaboración de autor.

Nótese un crecimiento sostenido a partir de 2011. Esto se debe a la entrada en vigor de la reforma a la Ley de Patentes que abre la posibilidad de otorgar la patente al inventor que primero registre el invento o proceso y no al primero en inventarlo, lo que disparó el número de litigios en más de $24 \%$. Los productos de consumo y biotecnología son los de mayor demanda representando un $17 \%$ y $14 \%$ del total de litigios respectivos.

La siguiente figura expone la distribución porcentual de litigios para las diez industrias de mayor participación en la actividad económica estadounidense durante el periodo 1995-2013. 
Figura 7. Distribución porcentual de litigios para las diez industrias de mayor participación en la actividad económica estadounidense durante el periodo 1995-2013

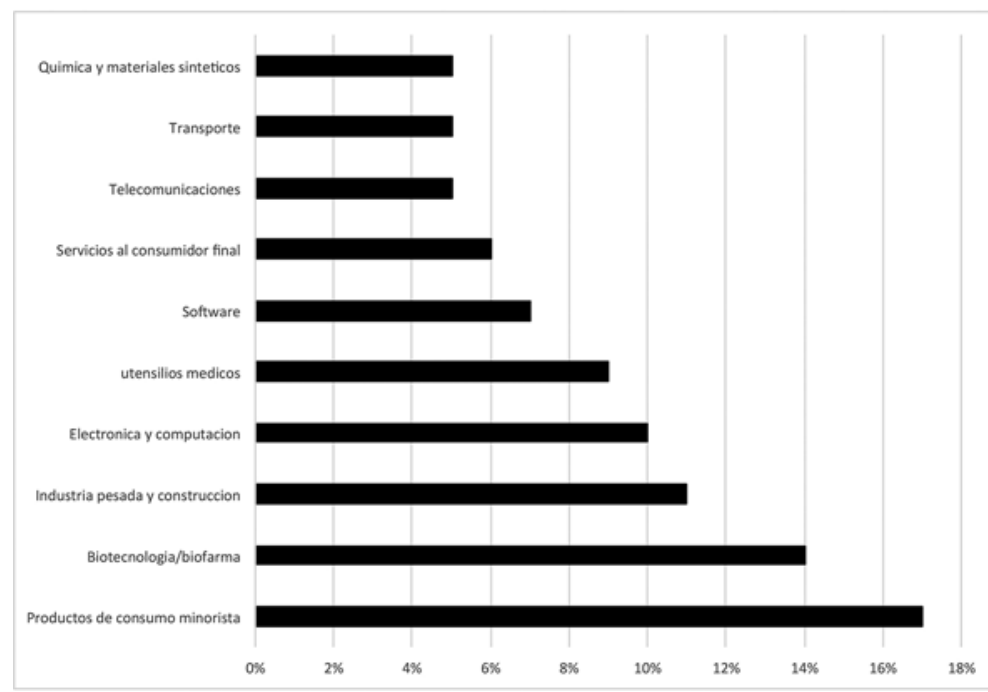

Fuente: Elaboración de autor.

Figura 8. Porcentaje de casos ganados por dueños de patentes en litigios durante el periodo 1995-2013

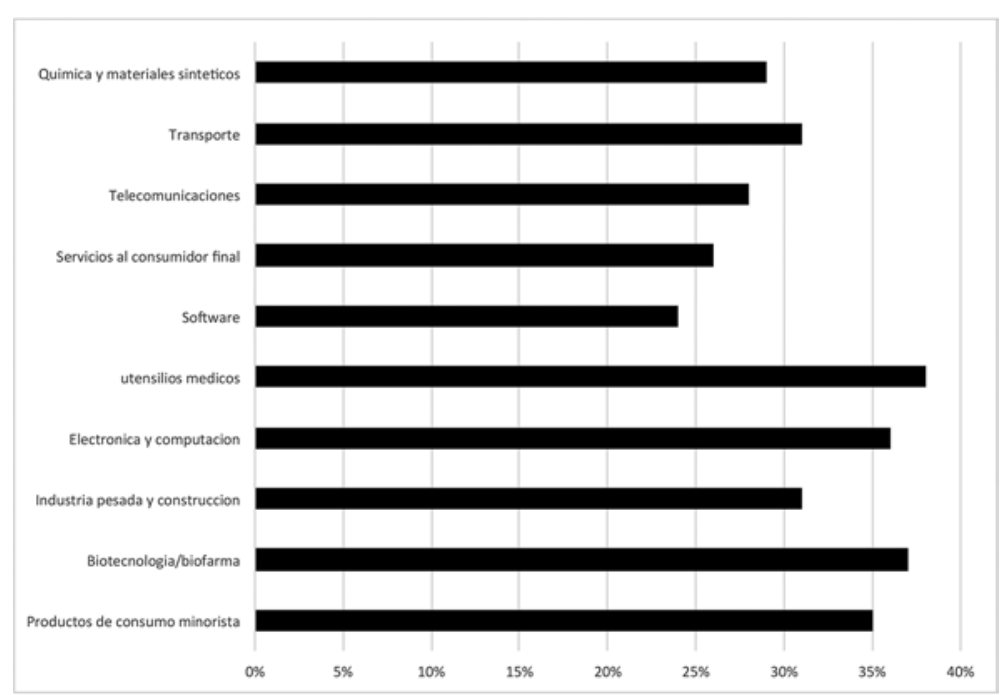

Fuente: Elaboración de autor. 
En ese sentido, el porcentaje de casos ganados por los dueños de patentes en litigios se encuentra alrededor del 35\% para las diez principales industrias del país. La siguiente figura expone el porcentaje de casos ganados por dueños de patentes en litigios durante el periodo 1995-2013. La creciente utilización y abuso del sistema judicial estadounidense con respeto a la defensa del derecho de propiedad intelectual de productos o procedimientos complejos y considerados obvios ha prolongado el periodo promedio de resolución de litigios, así como ha incrementado el monto de indemnización monetaria afectado directamente por la prolongación de una decisión judicial.

La siguiente figura expone en el eje izquierdo el monto promedio de indemnización en millones de dólares y en el eje derecho la duración promedio de litigio en años. Todo lo anterior dividido en cuatrienios desde 1995 hasta 2013. Nótese la correlación entre el crecimiento del periodo de tiempo de litigios en vigor hasta la fecha y el crecimiento en el monto de indemnización debido en muchos casos a la utilización indiscriminada del sistema legal para defender patentes en numerosos casos consideradas obvias por la comunidad en general.

Figura 9. Monto promedio de indemnización en millones de dólares (izquierda), duración promedio de litigio en años (derecha): 1995-2013

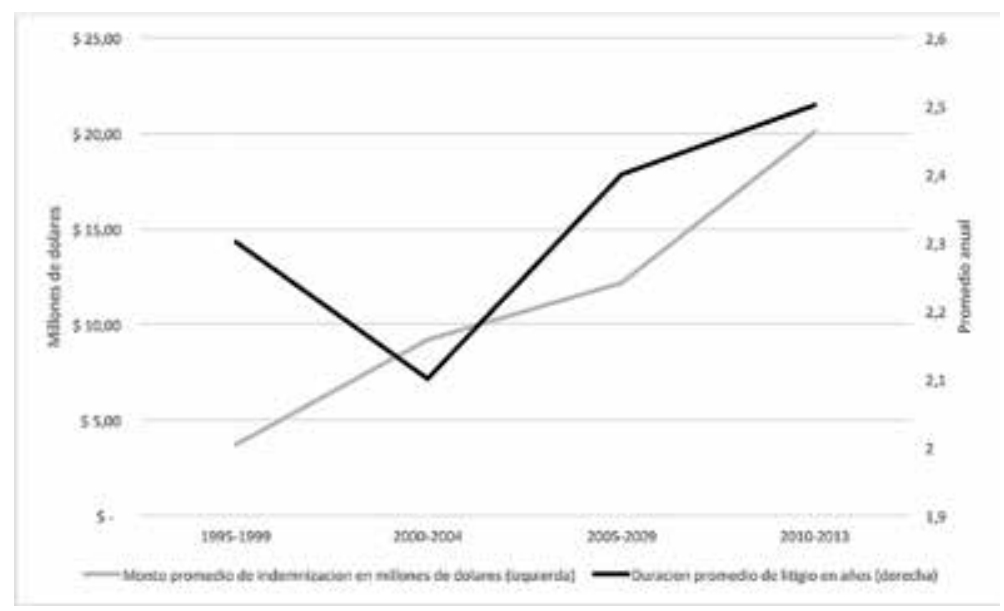

Fuente: Elaboración de autor.

Por último, se exponen los montos promedios de indemnización en las diez industrias de mayor actividad económica estadounidense. Sobresale el sector biotecnológico y farmacéutico con multas alrededor de US\$20 millones en promedio, debido a litigios de patentes sobre compuestos químicos en medicamentos comerciales y el sector de telecomunicaciones con alrededor de US\$ 22 millones en promedio por litigios alrededor de procesos y aplicaciones que involucran en más del $80 \%$ de los 
casos dispositivos móviles. Sin embargo, también se destaca la industria de utensilios médicos con más de US\$15 millones en promedio en multas, electrónica y computación con más de US\$10 millones. Todo esto hace suponer que si bien es indispensable la protección del derecho de propiedad intelectual, los litigios por patentes que en muchos casos son de dudoso aporte a la sociedad termina por distorsionar el mercado, ya que empresas y personas optan por competir en los estrados judiciales que en calidad y preferencia del producto hacia el consumidor final.

Figura 10. Promedio de multas por violación de derechos de propiedad intelectual por industria en millones de dólares de 2013

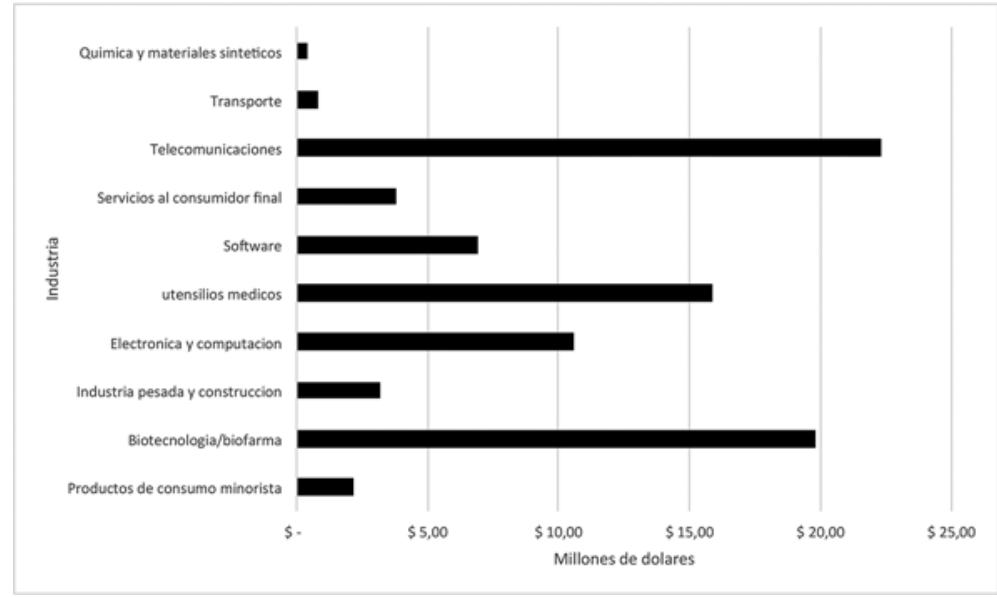

Fuente: Elaboración de autor.

\section{RECOMENDACIONES PARA LOGRAR MAYOR SINERGIA ENTRE EL MERCADO DE PATENTES Y EL PRINCIPIO DE LIBRE COMPETENCIA}

Para lograr mayor sinergia entre el mercado de patentes, sus autorizaciones y la no obstaculización de la libre competencia, además del mantenimiento del espíritu de innovación basado en la satisfacción del consumidor final, es necesario establecer una serie de modificaciones tanto a los procedimientos de otorgamiento de patentes que pueden ser consideradas obvias, como en el proceso de litigios de las mismas en caso de presunción de violación del derecho de propiedad intelectual. Es decir, si bien se busca que la patente como institución e instrumento de protección del derecho de propiedad intelectual se mantenga vigente en una economía de libre mercado, es necesario replantear el esquema de otorgamiento, reexaminación y litigio alrededor de esta. 
Primero, es necesario reforzar el procedimiento administrativo de revisión, oposición y reexaminación de una patente donde se involucren terceros, de manera que exista la posibilidad de evitar litigios en un futuro cercano por violación de derecho de propiedad intelectual. En ese sentido, es necesario especificar la prueba de sugestión con el fin de que se estudie si una patente se considera obvia más allá del conocimiento y opinión de un experto en la materia. En este caso, uno de los principales obstáculos y determinantes para el otorgamiento de patentes consideradas obvias es el vacío legal en cuanto a la examinación de un experto de si un invento o procedimiento no es solo el resultado del progreso ordinario de la tecnología. Aun no existen estándares muy específicos sobre qué es el "progreso ordinario de tecnología" enmarcado en la ley de patentes que termina por distorsionar el mercado y afectar el principio de libre competencia mencionada en la ley antimonopolio.

Segundo, es necesario dotar de recursos económicos y equipo especializado a la Oficina de Patentes que permita tramitar más rápido los procedimientos de solicitud, revisión y reexaminación de una patente, ya que en la actualidad su presupuesto es limitado y no cuenta con suficiente personal especializado para reexaminar una patente, ni para tramitar la solicitud de adquisición de esta en periodos menores a un año. Finalmente, es necesario considerar las implicaciones negativas en cuanto a costos y acceso práctico de un invento o procedimiento al consumidor intermedio y final en el otorgamiento de una patente, ya que los posteriores costos de uso de esta por parte de la comunidad a la que va dirigida aumentaría, estableciendo una discriminación de precios por medio de aumentos artificiales del costo de adquisición.

\section{CONSIDERACIONES FINALES}

El derecho de propiedad intelectual es característico de las economías de libre mercado donde se respeta la propiedad privada como fuente de libertades individuales y funcionamiento eficiente de los agentes económicos. Sin embargo, el otorgamiento indiscriminado de patentes por conceptos de creación y utilización sin una examinación rigurosa que incluye una mayor participación de terceros en el proceso promueve una distorsión de la competencia y un exceso de utilización del sistema legal que cuesta millones de dólares anuales a los contribuyentes en Estados Unidos. En ese sentido, es indispensable reforzar los términos legales por los cuales se le otorgan patentes a solicitantes a través de especificaciones normativas procedimentales en las pruebas de comercialización y sugestión, ya que en la actualidad estas cuentan con vacíos de los que no es posible diferenciar muchas veces un invento verdaderamente innovador, de otro que siga el principio de "progreso ordinario tecnológico". En ese sentido, reformar el otorgamiento de patentes a partir de la no obviedad de un producto basado en la participación limitada de terceros que permita alegaciones para evitar la concesión de productos que terminan perjudicando al consumidor final, es indispensable para lograr la no distorsión de precios e incentivos a los productores y consumidores donde los oferentes en muchos casos prefieren acudir al sistema 
legal para defender una idea y garantizar una participación en un nicho de mercado, que competir de forma transparente donde la innovación empresarial, el incentivo de consumo hacia el nicho objetivo y la competencia a partir de la productividad individual.

\section{REFERENCIAS}

Benegas, A. (1999). Apuntes sobre el concepto de copyright. Libertas, 2(29), 121-147. Buchanan, J. (1986). Los límites de la libertad: Entre la anarquía y el leviatán (pp. 89-91). Barcelona: Liberty Fund.

CDIP. (2011). Interface between exhaustion intellectual property rights and anticopetition law. WIPO Publications.

CDIP. (2011). Report on an analysis of economic/legal literature on intellectual property rights: A barrier to entry? CDIP Publications.

Cohen, W.M., Nelson, R.R., and Walsh, J. P. (2000). Protecting their intellectual assets: Appropriability conditions and why U.S. Manufacturing firms patent (or not). National Bureau of Economic Research, 4(89), 98.

Constitutional Rights Foundation. (enero, 2011). The origin of patents and copyright law. Washington D.C.: Constitutional Rights Foundation.

Cooper, T. (1838). The statutes at large of South Carolina: Acts from 1716 to 1752. A.S. Johnstown: Johnston.

Cuban, M. (2013). Lack of innovation as a consequence of law fragility (pp. 23-27). Washington D.C: Brooking Institution.

Denison, E. F. (1979). Accounting for slower economic growth. Brookings Institution. U.S: Washington D.C.

Dupree, H. (1986). Science in the Federal Government: A history of policies and activities (p. 43). Washington D.C: The Johns Hopkins University Press.

Foray. (1994). Production and distribution of knowledge in the new systems of innovation: The role of intellectual property rights. STI Review, 14(24), 98-99.

Gould, D., y Gruben, W. (1995). El papel de los derechos de la propiedad intelectual en el crecimiento económico. Economía Mexicana Nueva Epoca, 4(2), 23-25.

Hayek, F. A. (1948). 'Free' enterprise and competitive order. [1947]. En individualism and economic order (pp. 107-108). Chicago: University of Chicago Press.

Hurt, R. M. (1966). The economic rationale of copyright. American Economic Review, 56(134), 421-432.

Jaffe, A., and Trajtenberg. M. (2002). Patents, citations and innovations: A window on the knowledge economy. Massachusetts: MIT Press.

McKinsey y Co. (2012). Generating value in generics. McKinsey y Co. Publications.

Mochon, A. (2012). Brief history of patents and trademarks in America (pp. 24-25).

Pensacola: Brainstorming Pub. 
Mokyr, J. (1990). The lever of riches: Technological creativity and economic progress. Berlin: Oxford University Press.

Patent Act of 1793, Ch. 11, 1 Stat. 318-323 (february 21, 1793).

Patent Act of 1836, Ch. 357, 5 Stat. 117 (july 4, 1836).

Pérez y Soto, A. (2013). La información secuestrada: El modelo de servidumbre de Thomas Hobbes y su alternativa liberal austriaca en Friedrich August Von Hayek. (Tesis doctoral). Universidad Rey Juan Carlos de Madrid.

Pérez y Soto, A., Flores, K. (2013). La patente como límite a la innovación tecnológica. Procesos de Mercado: Revista Europea de Economía Política, 10(2), 107-109.

Plant, [Sir] A. (1974). The economic theory concerning patents for inventions (p. 24). San Diego: Oruro Editions.

Penrose, E. (1974). La economía del Sistema Internacional de Patentes (p. 40). Siglo XXI.

PWC. (2014). Patent litigation study as case volume leaps: damages continue general decline. Federal Register Monthly Review, 60(109), 12-13.

PWC Publications. (s.f.). Certain Patents. Selected Economic Essays and Addresses, 34(78), 35-56.

Watson, J. (2013). A history of the United States Patent Office. Official Press C.O. (pp. 123-125).

WIPO. (2014). Global innovation index: Who is leading innovation? WIPO Publications. 